\title{
Quantifying Leaf Variegation
}

\author{
Michael Marcotrigiano and Grant Hackett \\ Department of Plant and Soil Sciences, University of Massachusetts, Amherst, \\ MA 01003
}

Additional index words. chimeras, transposable genetic elements, image analysis

Variegation can be defined as the existence of two or more colors on a single organ. Its cause generally is genetic but can be physiological or pathological. Variegation may be caused by genetic mosaicism (i.e., when a plant possesses more than one genetically distinct cell line). Stable periclinal chimeras that possess shoot apices layered with albino and green cells have been isolated in many genera (Kirk and Tilney-Bassett, 1978) and can be used to describe organ development, as it is possible to determine the apical origin of cells in organs (Stewart, 1978). Intricate color patterns also can result from variable gene expression in genetically homogeneous plants and are frequently simply inherited (e.g., Rife, 1948). In other plants, transposable genetic elements cause random variegation by interfering with the expression of genes responsible for producing pigments (Fedoroff, 1984). The organs become flecked and streaked with uniquely colored patches of variable size. The number and size of the patches is determined by the developmental state of the organ at the time the transposition occurred. Understanding the temporal action of such genes depends on a technique that can quantify the amount of tissue of unique color on the organ. To do so, highly technical optical apparatus, such as a digital image analyzer, are effective (Smith et al., 1988) but expensive. In this paper, we describe a novel, inexpensive technique that uses a photocopy machine, transparencies, and a portable area meter.

Photocopy machines with adjustable contrast settings were tested for their ability to eliminate the image of the light portions of a leaf and resolve small spots. For the data presented, a Canon NP3325 photocopier (Canon, Lake Success, N.Y.) was used with Canon Type-D transparency film (item no. 9-70015-D1). The area meter was a LI-3000 portable area meter (LI-COR, Lincoln, Neb.) with a $50-\mathrm{cm}^{2}$ standard disk . To test the imaging procedure, the standard disk was placed on a white sheet of paper and photocopied five times to give five "image sheets." Each image sheet was photocopied onto a transparency film, and the film was passed

\footnotetext{
Received for publication 5 June 1992. Accepted for publication 15 Jan. 1993. Paper no. 3104 of the Massachusetts Agricultural Experiment Station. Mention of a trade name or brand does not imply that we or the Univ. of Massachusetts endorse a product. The cost of publishing this paper was defrayed in part by the payment of page charges. Under postal regulations, this paper therefore must be hereby marked advertisement solely to indicate this fact.
}

through the area meter 10 times. The mean of the 10 machine readings for each film was used to calculate a standard error (SE) for the procedure. The same method was used for leaves. When the disk was placed directly through the meter, the mean \pm SE for the area was $50.02 \pm 0.01 \mathrm{~cm}^{2}$. The transparencies of the image sheet of the disk gave a mean of $49.84 \pm 0.14 \mathrm{~cm}^{2}$; this result indicated that slight error accumulates during the procedure.

Leaves, from many genera, with a variety of variegation patterns and colors were tested. The color differences ranged from barely contrasting pinks and reds of variegated poinsettia (Euphorbia pulcherrima Willd) bracts to boldly contrasting patterns of albino and green tissues in chimeral leaves. A randomly chosen leaf was taken from several plants. Leaves taped to white paper with clear tape were photocopied by varying the contrast setting until the lighter regions of the leaf did not make an image on the paper. From this image sheet, a transparency was produced. Since the transparency sheet is clear, it can be passed through the leaf area meter to determine the area imprinted on it without dissecting out the image. With the exception of Dracaena, the error term associated with the procedure for leaves was even less than that for the standard disk (Table 1). This procedure could not be used on all species. The contrast between regions of unique color on Euphorbia, Sansevieria, and Coleus was not great enough to eliminate the lighter color of the leaf on the image sheet completely, while in other species, this was achieved easily by adjusting contrast settings (Fig.1).

Our technique is useful for many applications for which low-cost imaging is necessary. It does not compare to costly image analyzers that have useful features, including the ability to count spots, assign numeric values to different colors, and be linked to computers. However, our technique is inexpensive and useful for making a permanent record of the variegation patterns of perishable leaves and for quantifying leaf variegation in several species.

Table 1. The mean \pm SE for the area of dark image derived from transparencies of image sheets.

\begin{tabular}{lr}
\hline \hline Species $^{2}$ & $\begin{array}{c}\text { Mean area } \pm \mathrm{SE} \\
\left(\mathrm{cm}^{2}\right)\end{array}$ \\
\hline Dracaena surculosa & $17.92 \pm 0.16$ \\
Cyperus alternifolius Variegata & $6.57 \pm 0.04$ \\
Hedera helix (cultivar unknown) & $9.51 \pm 0.04$ \\
Nicotiana tabacum (chimera) & $9.39 \pm 0.03$ \\
\hline
\end{tabular}

${ }^{2}$ The leaves used to derive this data set were not the same leaves pictured in Fig. 1.
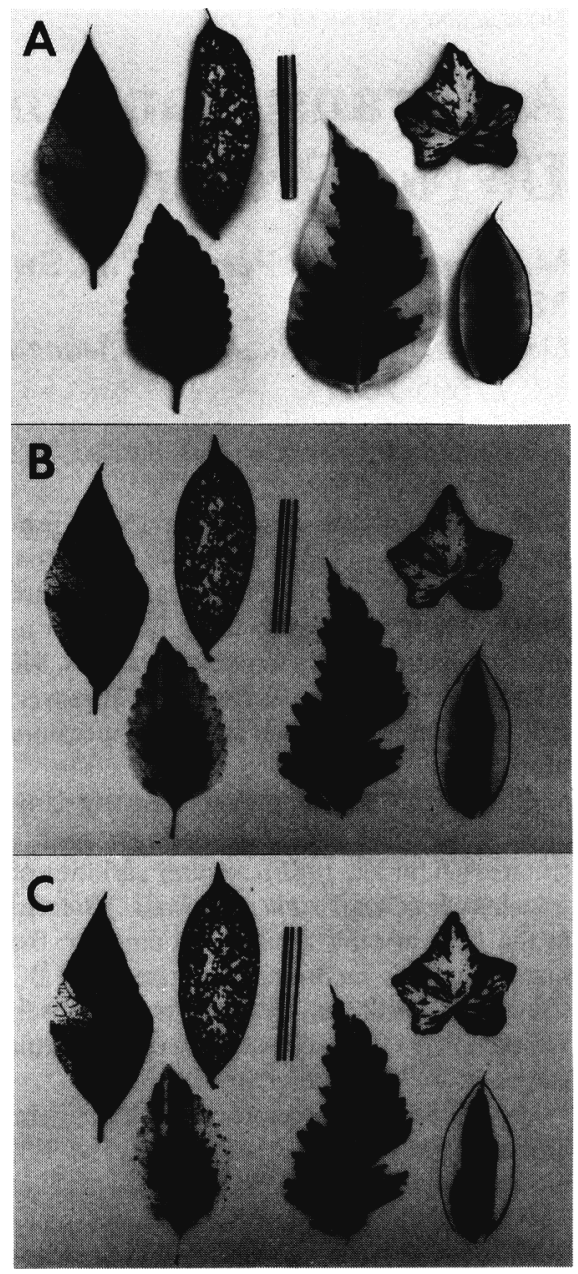

Fig. 1. (A) Variegated leaves of (top row, left to right) Euphorbia pulcherrima 'Jingle Bells' (red and pink variegated bract), Dracaena surculosa Lindl. (cream and green), Cyperus alternifolius L. 'Variegata' (white and green leaf piece), and Hedera helix L. (unknown green, gray-green, and white clone); and (bottom row, left to right) Coleus Xhybridus Voss. 'Golden Bedder' (chartreuse and maroon); Nicotiana tabacum L. 'Xanthi' (green and white chimera); and Sansevieria trifasciata Prain. 'Golden Hahnii' (yellow and green). (B) "Image sheet" (i.e., photocopy) of leaves in Fig. 1A. (C) Transparency film (placed on top of white paper for photography) of image sheet in Fig. 1B.

\section{Literature Cited}

Fedoroff, N.V. 1984. Transposable genetic elements in maize. Sci. Amer. 250(6):84-90, 95-98.

Kirk, J.T.O. and R.A.E. Tilney-Bassett. 1978. The plastids. Elsevier/North-Holland Biomedical, Amsterdam.

Rife, D.C. 1948. Simply inherited variations in coleus. J. Hered. 39:85-91.

Smith, M.A.L., L.A. Spomer, and R.K.D. Cowen. 1988. Image analysis to quantify the expression of an unstable allele. J. Hered. 79:147-150.

Stewart, R.N. 1978. Ontogeny of the primary body in chimeral forms of higher plants, p. 131-160. In: S. Subtelny and I.M. Sussex (eds.). The clonal basis of development. Academic, New York. 